\title{
The role of phonological processes in determining the vowel inventory of Brazilian Portuguese
}

\author{
Arthur Pereira Santana \\ University of São Paulo \\ arthurpereirasantana@gmail.com
}

\begin{abstract}
This article deals with the non-final posttonic vowel subsystem of Brazilian Portuguese, specifically it questions if the high-mid vowels /e, 0 / have undergone neutralization in this position. Three accounts have been provided so far to answer this question. Câmara Jr. (1999) proposes that the nonfinal posttonic subsystem is composed of four vowels /i, e, a, u/; Bisol (2003) advocates for a three-vowel subsystem /i, a, u/, and Ribeiro (2007) defends a five-vowel subsystem /i, e, a, o, u/. In this paper, I show that mid-vowel alternation in nonfinal posttonic context is the key to defining what the vowel subsystem is, which must be composed of five vowels /i, e, a, o, u/; however, differently to what has been proposed by Ribeiro (2007) for whom mid-vowel alternation is a case of lexical diffusion, I show that a rule-based approach is more explanatory of the phenomena.
\end{abstract}

Keywords: vowel subsystem; mid vowels; neutralization; nonfinal posttonic; vowel inventory

\section{Introduction}

Following the tendency of Romance languages, Brazilian Portuguese (hereafter, BP) has a vowel system consisting of seven segments in stressed position: / a , $\varepsilon$, e, i, ə, o, u/. It also has a three-syllable window for stress assignment, i.e., main stress falls on one of the three final syllables of words. As there is no limit for word size, unstressed contexts can either be pretonic or posttonic. Câmara Jr. (1999) argues that the contrast between low-mid and high-mid vowels is lost in pretonic syllables and the subsystem becomes one of five vowels: / a, e, i, o, u/. In word final posttonic syllables, the distinction between high-mid and high vowels is also lost, resulting in a yet simpler subsystem of three vowels: / a, i, u/. Both claims are general consensuses in the literature (Wetzels 1992; Bisol 2003; among others).

The nonfinal posttonic subsystem (NFP from now on) only exists in words with antepenultimate stress (e.g., TÍpico 'typical', aBÓbora 'pumpkin', where NFP is indicated in bold). Differently from the other vowel sub- 
systems, authors have not found an agreement on NFP's vowel configuration. Câmara Jr. (1990) first claims that in NFP there is a high frequency of alternation between posterior high-mid/high vowels $(s e M A f[0] r o \sim s e$ $M A f[\mathrm{u}]$ ro 'semaphore') in the Rio de Janeiro dialect, which led him to propose that this subsystem should be made up of four vowels /a, e, i, u/ (/o/ being neutralized).

Bisol (2003) argues against Câmara Jr.'s (1990) proposal by showing that the alternation also occurs with anterior high-mid/high vowels (TÍqu[e]te $\sim$ TÍqu[i]te 'ticket'). As there is no evidence of contrast being produced by high-mid vowels in NFP, Bisol proposes that the subsystem should be of three vowels, similar to the one in final posttonic context $/ \mathrm{a}, \mathrm{i}, \mathrm{u} /$.

Ribeiro's (2007) view is that NFP's vowel inventory consists of five vowels /i, e, a, o, u/, as, even though mid-vowel alternation occurs in the position, high-mid vowels are still frequently produced. According to this account, mid-vowel alternation should be seen as a case of lexical diffusion.

These analyses capture many facts of the Southern dialects of BP, but fail to explain the predictability of mid-vowel raising in NFP besides not addressing what happens in northern dialects of BP, in which lowmid vowels may also surface in this position (e.g., $C \hat{A} m[\varepsilon] r a$ 'camera', reCÍpr [ə] ca 'reciprocal').

In this paper, I argue that it is not only by looking at lexical contrast, but specially by considering the phonological processes that affect vowel height in NFP, in both southern and northern dialects, that we can find enough evidence of what the underlying representation of the subsystem is, which must consist of five vowels /a, e, i, o, u/. I also show that a rule-based approach better captures the facts observed in previous work. In section 2, I present important aspects of BP's vowel pattern and review the existing accounts for NFP subsystem. In section 3, I revisit some experimental data analyzed in Santana (2016); and in section 4, I focus on the phonological implication of mid-vowel alternation in NFP, argue why the five-vowel subsystem better captures empirical data and show how it is possible to formalize the neutralization rule that produces the five-vowel subsystem in NFP. 


\section{Vowel patterns in Brazilian Portuguese}

\subsection{Feature specification and neutralization rules}

The analysis hereby proposed will be developed on the theoretical background of Autosegmental Phonology (Goldsmith 1990). In autosegmental terms, Clements (1991) proposes that vowel heights form a phonological space which is divided into a series of registers by [open] features. Registers can be subdivided to create the language's abstract vowel space. In the case of a language such as Italian or Portuguese, with an inventory of seven vowels, three [open] features are required to specify all vowels and can be hierarchically organized as follows.

(1) Vowel height registry (Clements 1991)

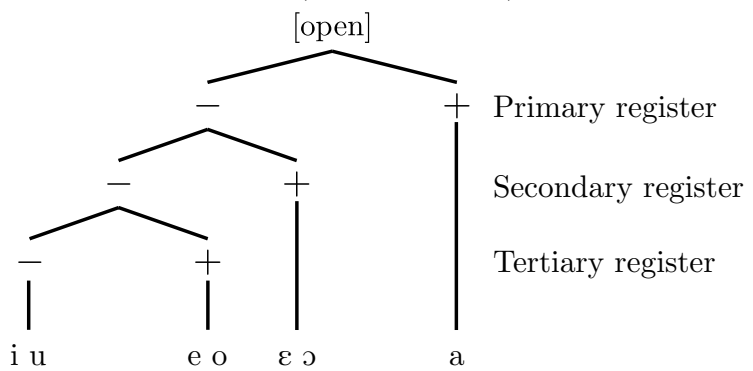

Following this analysis, languages vary on the number of existing registers as well as on the features that specify each vowel. For BP, Wetzels (1992) proposes that [+open1] distinguishes low and non-low vowels; [+open2] contrasts high from high-mid vowels and [+open3] differentiates high-mid from low-mid vowels (see (2)).

(2) BP's [open] feature values in stressed syllables

$\begin{array}{lcccc}\text { Aperture } & \mathrm{i} / \mathrm{u} & \mathrm{e} / \mathrm{o} & \varepsilon / \mathrm{J} & \mathrm{a} \\ \text { open1 } & - & - & - & + \\ \text { open2 } & - & + & + & + \\ \text { open3 } & - & - & + & +\end{array}$

As previously mentioned, the phonemic character of the seven oral vowels in stressed position in BP has been established beyond doubt. It has also been mentioned that the contrast between low-mid and high-mid vowels outside the stressed syllable is lost. Note that the quality of $[\mathrm{i}],[\mathrm{e}],[\mathrm{u}],[\mathrm{o}]$ and $[\mathrm{a}]$ in stressed syllables remains unaltered when a suffix causes stress shift and the stressed syllable becomes pretonic (3). However, this is not the 
case for $[\varepsilon]$ and $[\supset]$, indicated in italics. As one can see, with the adjunction of a suffix (caFE > cafeTEIra 'coffee' > 'coffee maker', PORta $>$ porTEIro 'door' $>$ 'door man') stressed low-mid vowels $[\varepsilon$, o] become pretonic highmid [e, o]. That is, low-mid vowels are neutralized outside the stressed syllable in favor of high-mid vowels.

(3) Alternation between vowels in stressed and pretonic context

Stressed

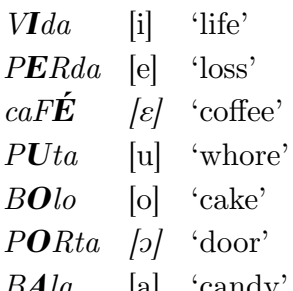

Pretonic

viDENte [i] 'fortune teller'

perDIdo [e] 'lost'

cafe TEIra [e] 'coffee machine'

pиTEIro [u] 'whorehouse'

boLEIro [o] 'cake maker'

porTEIro [o] 'doorman'

baLEIro [a] 'candy maker'

To account for the loss of distinction between low-mid and high-mid vowels outside the stressed syllable, Wetzels (1992) proposes a rule that neutralizes [+open3]. As the distinction of low-mid vowels is lost in all unstressed contexts, not only in pretonic syllables, the author argues that the domain of the rule must be the phonological word.

Regarding the final posttonic context, Wetzels proposes that [+open2] is also neutralized, the reason for why there is no distinction between high-mid and high vowels in word final position in BP. As illustrated in (4) below, high-mid vowels /e, o/ are not contrastive in final posttonic context and are produced as high vowels (VERd[i] 'green', PAt[u] 'duck').

(4) Alternation between vowels in stressed and pretonic context

\begin{tabular}{|c|c|c|c|}
\hline \multicolumn{2}{|l|}{ Stressed } & \multicolumn{2}{|l|}{ Posttonic } \\
\hline $\operatorname{par} T \mathbf{I} d o$ & 'broken' & parte [i] & 'part' \\
\hline$V \boldsymbol{E} R d e$ & 'green' & $V E R d \boldsymbol{e}$ & 'green' \\
\hline $\operatorname{taT} \boldsymbol{U}$ & 'armadillo' & TAto & 'tact' \\
\hline past $\mathrm{O} R$ & 'minister' & PAto & 'duck' \\
\hline tacaCÁ & [a] 'regional soup' & $t a C A c \boldsymbol{a}$ [a] & 'skunk' \\
\hline
\end{tabular}

Wetzels (2011) argues that neutralization should not be understood as a process of feature deletion, but as a process that changes the value of the feature by their opposite value in the tier on which contrast is defined. According to the author, evidence for this comes from a rule of affrication in BP that must take /i/ in its conditioning environment. Since the rule occurs in every context (stressed: dia ['dzia] 'day'; pretonic: dinheiro [dzi'nejrø] 'money'; nonfinal posttonic: Édipo ['edzip»] 'Oedipus'; final 
posttonic: promete [pro'met $\int_{\mathrm{I}}$ ] 'promises') and different [open] features are neutralized depending on the context, it would be impossible to define /i/, and match /i/ and /i/ alone, in all the subsystems in which affrication applies if one assumes features were deleted after being neutralized.

By assuming that neutralization is a process of feature change, Wetzels proposed the feature specification of the vowels in pretonic and final posttonic as presented in (5) and (6).

(5) Feature specification in pretonic

Aperture i/u e/o [e/o] a

$\begin{array}{llll}\text { open1 } & - & - & +\end{array}$

$\begin{array}{llll}\text { open2 } & - & + & +\end{array}$

open3 - $\quad-\quad+$
(6) Feature specification in pretonic

Aperture i/u a

open1 - $\quad+$

open2 - $\quad+$

open3 $\quad-\quad+$

Although vowels have undergone neutralization, the number of features remains the same. Consequently, /i/ has [-open1, -open2, -open3] in its configuration in all contexts and can be defined as the trigger of the affrication rule in terms of feature specification. I will show in section 3 that mid-vowel alternation in NFP is also a piece of evidence for neutralization as a feature-change process.

In sum, I assume Wetzels' (1992) account that the seven-vowel system in stressed position $/ \mathrm{i}, \mathrm{e}, \varepsilon, \mathrm{a}, \mathrm{\jmath}, \mathrm{o}, \mathrm{u} /$ is reduced to a five-vowel subsystem outside the stressed syllable /i, e, a, o, u/ due to the neutralization of [open3]; and the neutralization of [open2] further reduces the subsystem to a three-vowel /i, a, u/ in unstressed word-final context. [open1] is never neutralized as the distinction of high $/ \mathrm{i}, \mathrm{u} /$ and low $/ \mathrm{a} /$ is never lost.

\subsection{Accounts of the NFP subsystem}

Antepenultimate stress (e.g., SÍ.la.ba 'syllable', LÂA.pa.da 'light bulb') is the least frequent stress pattern in the lexicon of the language. According to Cintra (1997), only $7 \%$ of words in Portuguese have antepenultimate stress and many authors argue that, due to the fact that most words with antepenultimate stress are borrowings, technical or simply unfrequently used, it is an unnatural stress pattern to the language (Araújo 2007). Still, it is only in words with antepenultimate stress that nonfinal posttonic syllables exist.

Câmara Jr. (1990) was the first author who addressed the vowel subsystem in NFP context. The author notes that there is no minimal pair in the language that could serve as straightforward evidence for the phonemic distinction between high-mid /e, o/ and high vowels $/ \mathrm{i}, \mathrm{u} /$. The author 
also notes a strong tendency for the mid-vowel /o/ to surface as high $[\mathrm{u}]$ in the Rio de Janeiro dialect (e.g., diálogo $\sim \operatorname{dial}[\mathrm{u}]$ go 'dialogue', apóstrofo $\sim$ apóstr [u]fo 'apostrophe'). However, he highlights the fact that while a word such as TÉp/i]do 'tepid' must always be produced with a high vowel [i] in NFP, HÉt/e/ro 'straight' must always have a high-mid [e] following the stressed syllable.

These observations led Câmara Jr. to propose that in NFP the back vowel /o/ has undergone neutralization, but the same is not true for $/ \mathrm{e} /$, i.e., the front mid-vowel is still part of the subsystem. This view has a very important consequence, it creates an asymmetrical vowel subsystem /a, e, $\mathrm{i}, \mathrm{u} /$. One would recall that no other vowel subsystem is asymmetrical in BP. Besides this discrepancy, when looking at Câmara Jr.'s proposal from an autosegmental perspective, the formalization seems problematic, as the same [open] feature that guarantees the distinction for the back vowels, also does it for the front vowels (see (2) and (3) again).

Wetzels' (1992) attempt to capture Câmara Jr.'s (1990) proposal in autosegmental terms is by restricting the neutralization rule to only labial vowels. The author also proposes that the domain of application must be the stress foot, as NFP syllables will either be the weak member of the stress foot or the sole member of a degenerated foot. However, a syllable that is the weak member of the stress foot or constitutes by itself a degenerated foot will not necessarily always be an NFP syllable, so it is not completely clear how the rule is only restricted to back vowels in NFP context.

Bisol (2003) was the one who first noted the asymmetry issue in Câmara Jr.'s account. She argues that NFP's subsystem must be symmetrical, in accordance with the default pattern in BP. She highlights that the sociolinguistic study carried out by Vieira (2002) in the south of Brazil shows that the prominent alternation from high-mid to high vowel in NFP is not only restricted to back vowels $([\mathrm{o}] \sim[\mathrm{u}]$, around $80 \%)$, but also occurs with front vowels, even though less frequently ([e] [i], around $40 \%)$.

The alternation of high-mid and high vowels is not unprecedented in the phonology of BP. Mid-vowel harmony is an extremely productive process in pretonic syllables. As defined by Bisol and Veloso (2016), midvowel harmony in BP is a variable process of regressive assimilation of pretonic mid-vowels to a following high vowel (e.g., $m[\mathrm{e}] n[\mathrm{i}] n o \sim m[\mathrm{i}] n[\mathrm{i}] n o$ 'boy', $c[\mathrm{o}] s t[\mathrm{u}] r a \sim c[\mathrm{u}] s t[\mathrm{u}] r a$ 'sewing'). In Northern Dialects of BP, the pretonic mid-vowels may also assimilate to a following low or low-mid vowel (e.g., $p[\mathrm{e}] g[\mathrm{a}] d a \sim p[\varepsilon] g[\mathrm{a}] d a$ 'footprint', $g[\mathrm{o}] s t[\rho] s a \sim g[\rho] s t[\lrcorner] s a$ 'tasty, fem.' . 
However, in Vieira's study, no phonological variables were statistically significant in a way that would allow for the formalization of an assimilation rule in NFP. Following this claim, Bisol assumes that what causes the raising of mid-vowels is, in fact, a straightforward neutralization rule that yields high vowels as its output. Also, Bisol believes that the rate of alternation is evidence that NFP's subsystem is changing to a subsystem of three vowels similar to the one in final posttonic context, even though the change has not reached its completion in any BP dialects.

There are several issues with these claims. First, Vieira (2002) did not choose to control the segments to the right of the mid-vowels in NFP as independent variables. This is unexpected because BP is a language with a tendency for regressive phonological processes (cf. Cagliari 1997). Consequently, it would be impossible to attest if there was any significant correlation with segments that followed the mid-vowel in NFP, as the relevant variables were left out of the analysis.

The second issue falls on Bisol's (2003) proposal. The asymmetry problem is solved with the three-vowel subsystem /a, i, u/, however, as previously mentioned, front high vowels are blocked from emerging in NFP in certain words (e.g., *núm[i] ro 'number, *op[i] ra 'opera' and *hét[i] ro 'straight'). We could expect variability, but if we assume that $/ \mathrm{i} /$ is the only underlying front vowel in the context, [i] should not be blocked from being phonetically produced. Finally, even if the subsystem was changing to a three vowels configuration, the question of what is the current status of mid-vowels in the subsystem still needs to be answered.

Azevedo (2005) describes NFP subsystem as composed of five vowels /i, e, a, o, u/. However, the author does not address the implications of this configuration or mid-vowel alternation in the NFP position.

Ribeiro (2007) also defends the idea of a five-vowel subsystem and proposes that mid-vowel alternation in NFP is a case of lexical diffusion. The author analyzes a corpus of 1820 tokens and the statistical analysis shows that of the controlled variables (namely, preceding and following consonants, height of the stressed vowel, position in the word, speech rate, lexical item, individual, social status and level of education) only the lexical item and individual were variables correlated to the surfacing of high vowels in NFP. Therefore the author sees it as a case of lexical diffusion.

Similarly to Vieira (2002), Ribeiro (2007) did not choose to control the height of the vowel in word final position either, which, again, is unexpected given the general tendency for regressive phonological processes in the language and the productivity of mid-vowel harmony in other unstressed context (pretonic). 
It seems reasonable to say that mid-vowel alternation is the key to addressing vowel configuration in NFP. However, none of the previous accounts addressed a crucial matter, which is the fact that in northern dialects of BP, mid-vowel alternation in NFP not only implies the surfac-

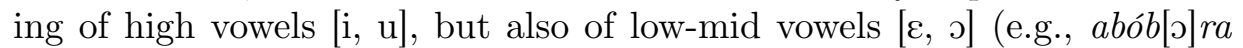
'pumpkin', câm[ع]ra 'camera'). This will be addressed in more detail in the next section.

\section{Mid vowel alternation in NFP}

Even though $/ \varepsilon, \mathrm{o} /$ have undergone neutralization outside the stressed syllable, the low-mid vowels $[\varepsilon, \rho]$ may also variably surface in unstressed syllables in Northern Dialects (ND) of Brazilian Portuguese (see (7), where stressed syllables are in capitals). This is one of the main phonological distinctions that differentiates northern from Southern Dialects (SD), as low-mid vowels in SD are generally blocked outside the stressed syllable.

(7) Low-mid vowels in NFP - ND

Pretonic

p $[\varepsilon]$ TEca

$\mathrm{m}[\varepsilon] \mathrm{rCAdo}$

$\mathrm{p}[\varepsilon] \mathrm{rFUme}$

c[o]LÓquio

$\mathrm{n}[\mathrm{o}] \mathrm{rDESte}$

t[o]rMENto

\author{
Nonfinal posttonic \\ CÂm[ع]ra 'camera' \\ NÁd[E]ga 'buttock' \\ VÉRt[c]bra 'vertebra' \\ aGRÍc[o]la 'agricultural' \\ aBÓb[s]ra 'pumpkin' \\ reCÍpr[ə]ca 'reciprocal'
}

The fact that low-mid vowels may also surface in NFP is, yet, another issue for Bisol's account. If we assume that the subsystem in NFP is /a, i, u/, it would be possible to propose a phonological rule targeting [-open2] to lower one height-level $(/ \mathrm{i} / \sim[\mathrm{e}] ; / \mathrm{u} / \sim[\mathrm{o}])$. However, in order to derive lowmid vowels $[\varepsilon$, , ] from underlying high-vowels $/ \mathrm{i}, \mathrm{u} /$, one would have to propose a rule targeting both [-open2] and [-open3] to lower two height levels. Firstly, this would be odd for a language such as Portuguese, as there is no record of a process similar to this existing in the language, or in other Romance Languages as far as I can tell; secondly, this would also be problematic to be captured in autosegmental terms, as the model only allows for one feature to be spread at a time unless they form a constituent (Goldsmith 1990), for which there is no evidences. Note that low-mid vowels in NFP are also an issue for Câmara Jr.'s account, but only with regard to the high-mid back vowel, which, he proposes, has been neutralized. 
Ribeiro (2007) does not address low-mid vowels in NFP, as she analyzed the Belo Horizonte dialect, representative of SD. One could assume that if the surfacing of high vowels in NFP is really a case of lexical diffusion as proposed by Ribeiro, so is the surfacing of low-mid vowels in ND. However, in order to support this hypothesis, it is crucial that mid-vowel alternation in NFP is not predictable, and some relevant phonological variables were left out of Ribeiro's experiment.

Aiming to fully understand mid-vowel alternation in NFP, an experimental study was carried out by Santana (2016). The phonologically balanced and acoustically analyzed corpus was composed of words (and nonce words) with antepenultimate stress and mid-vowels in NFP. The controlled phonological variables were the height and place of articulation of the adjacent vowels and consonants. Forty speakers of two Brazilian cities, São Paulo and São Luís, which are representatives of SD and ND, respectively, were recorded. The experiment resulted in a corpus of 4720 tokens.

As can be seen in Table 1, high vowels were less frequent than highmid vowels and, in ND, [i, u] were even less frequent than $[\varepsilon, \jmath]$. This does not support the claim of an imminent change to a three vowel NFP subsystem as made by Bisol, since if this was the case, one would expect the frequency of high vowels to be much higher.

Table 1: Frequency rate of mid vowels in NFP

\begin{tabular}{cccccccc}
\hline & {$[\mathrm{i}]$} & {$[\mathrm{e}]$} & {$[\varepsilon]$} & {$[\mathrm{u}]$} & {$[\mathrm{o}]$} & {$[\mathrm{\jmath}]$} & Total \\
\hline SD & 149 & 1031 & 0 & 149 & 1031 & 0 & 2360 \\
& $(12,6 \%)$ & $(87,4 \%)$ & $(0 \%)$ & $(12,9 \%)$ & $(87,4 \%)$ & $(0 \%)$ & \\
ND & 107 & 755 & 318 & 100 & 831 & 249 & 2360 \\
& $(9 \%)$ & $(64 \%)$ & $(27 \%)$ & $(8,4 \%)$ & $(70,4 \%)$ & $(21,2 \%)$ & \\
\hline
\end{tabular}

The inferential statistical analysis ${ }^{1}$ showed that the same tendency was found for the emergency of high vowels in both northern and southern dialects: high vowels were correlated with the place of articulation of the final posttonic vowel. Table 2 below displays the results drawn from the SD data. Note that [i] surfaced significantly more in NFP when the final posttonic vowel was also a coronal vowel (e.g., hipót [i] $s[\mathrm{i}]$ 'hypothesis', tíqu[i]tti] 'ticket'). Similarly, $[u]$ surfaced significantly more when the final vowel was also a labial vowel (e.g., antíd $[\mathrm{u}] t[\mathrm{u}]$ 'antidote', êx $[\mathrm{u}] d[\mathrm{u}]$ 'exodus').

\footnotetext{
${ }^{1}$ A chi-square test was used in the statistical analysis.
} 
Table 2: NFP vowel $\times$ Place of articulation of the Final posttonic vowel - SD

\begin{tabular}{|c|c|c|c|c|c|c|c|c|c|}
\hline & \multicolumn{3}{|c|}{ Place of articulation } & \multirow[b]{2}{*}{ Total } & & \multicolumn{3}{|c|}{ Place of articulation } & \multirow[b]{2}{*}{ Total } \\
\hline NFP vowel & Labial & Coronal & Dorsal & & NFP vowel & Labial & Coronal & Dorsal & \\
\hline [e] & 381 & 269 & 381 & 1.031 & [o] & 302 & 328 & 358 & 988 \\
\hline [i] & 19 & 111 & 19 & 149 & {$[\mathrm{u}]$} & 98 & 52 & 42 & 192 \\
\hline Total & 400 & 380 & 400 & 1.180 & Total & 400 & 380 & 400 & 1.180 \\
\hline \multicolumn{6}{|c|}{$p<0.001$} & \multicolumn{4}{|c|}{$p<0.001$} \\
\hline
\end{tabular}

The same tendency was found in the results obtained with the ND data. As one can see in Table 3, [i] and [u] were significantly more frequent when, respectively, a coronal and a labial vowels were in final posttonic context. ${ }^{2}$

Table 3: NFP vowel $\times$ Place of articulation of the Final posttonic vowel - ND

\begin{tabular}{|c|c|c|c|c|c|c|c|c|c|}
\hline \multirow[b]{2}{*}{ NFP vowel } & \multicolumn{3}{|c|}{ Place of articulation } & \multirow[b]{2}{*}{ Total } & \multirow[b]{2}{*}{ NFP vowel } & \multicolumn{3}{|c|}{ Place of articulation } & \multirow[b]{2}{*}{ Total } \\
\hline & Labial & Coronal & Dorsal & & & Labial & Coronal & Dorsal & \\
\hline$[\varepsilon]$ & 116 & 57 & 145 & 318 & {$[\supset]$} & 49 & 62 & 138 & 249 \\
\hline$[\mathrm{e}]$ & 267 & 262 & 226 & 755 & {$[\mathrm{o}]$} & 308 & 287 & 236 & 831 \\
\hline [i] & 17 & 61 & 29 & 107 & {$[\mathrm{u}]$} & 43 & 31 & 26 & 100 \\
\hline Total & 400 & 380 & 400 & 1.180 & Total & 400 & 380 & 400 & 1.180 \\
\hline \multicolumn{6}{|c|}{$p<0.001$} & \multicolumn{4}{|c|}{$p<0.001$} \\
\hline
\end{tabular}

One could argue that the correlation was not with the place of articulation, but with the height of the final posttonic vowel, as in the three-vowel final posttonic subsystem labial and coronal vowels are also high vowels. However, Santana (2016) argues that the height of the final posttonic vowel was a controlled variable and the correlation was not attested. As it would be odd to assume that a place feature is affecting the [open] feature of the preceding vowel, the author proposes a rule that spreads the whole vocalic

${ }^{2}$ It is important to highlight that, although there is a clear tendency for an assimilatory process, this is a variable process similar to mid-vowel harmony in pretonic syllables. Therefore, some unexpected cases do exist and require further analysis. (see Santana 2015 for a full description of the exceptions). 
node from the final posttonic vowel to the preceding nonfinal posttonic vowel, that is, full assimilation occurs ${ }^{3}$ (see (8)).

(8) Vocalic node assimilation rule

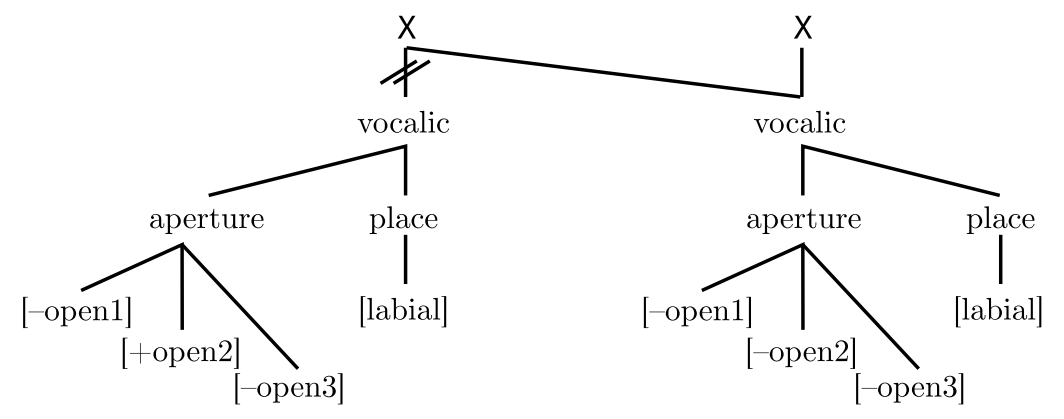

Santana (2016) also tries to find a logical pattern that would predict the surfacing of high-mid vowels [e, o] in NFP, but none could be found. With respect to the surfacing of low-mid vowel $[\varepsilon, \jmath]$, the correlation was observed with the dorsal vowel in final posttonic position for both back and front vowels (e.g., nád $[\varepsilon] g[\mathrm{a}]$ 'buttock', désp[ə]t[a] 'despot'). However, in this case, the correlation was also statistically attested with the height of the vowel. Recall that /a/ is the only dorsal and open vowel in final posttonic context. The assimilation could not be of the vocalic node, as is the case for the high vowels, because the mid-vowel in NFP would assimilate the [dorsal] feature and it would be produced as [a]. Santana formalized the rule for the surfacing of low-mid vowels in NFP as a spreading of [+open3] from the final posttonic / a/ to the preceding nonfinal posttonic mid vowel, as represented in (9).

(9) [+open3] assimilation rule

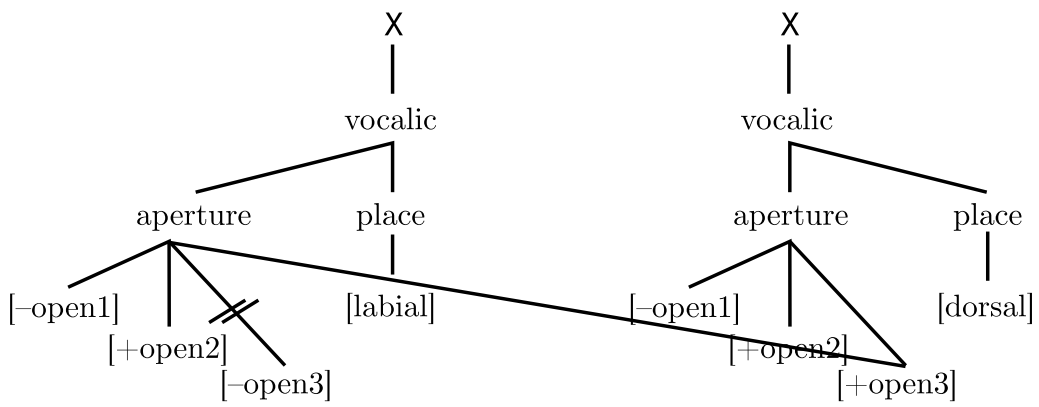

${ }^{3}$ One of the reasons I classify full assimilation as less odd has to do with the fact that this kind of process has been previously observed in the phonology of the language (Bisol \& Veloso 2016). 
The fact that final posttonic vowels trigger mid-vowel alternation in NFP has an important consequence for the concept of neutralization in phonological theory, it shows that the classical approach to neutralization as a feature deletion process (Clements \& Hume 1995) is problematic.

As previously mentioned, in final posttonic context, both [open3] and [open2] have undergone neutralization, which results in a three-vowel subsystem /i, a, u/. However, as final posttonic vowels trigger mid-vowel alternation in NFP, then the features required for the alternation to occur, i.e., the features to be spread, need to be specified for the vowels in final posttonic context. If we assume that neutralization is a feature deletion process, then neither [open2] nor [open3] would be available in this context, therefore, the correlation between mid-vowel alternation in NFP and the vowels in final posttonic context should not exist.

However, by assuming that neutralization is a mechanism that changes the value of the feature that guarantees the distinction for its opposite value (Wetzels 2011), then the features required for the surfacing of high vowels in NFP ([-open2] and [-open3]) are specified for the high vowels in final posttonic context. The same way, [+open3], which is necessary for the surfacing of low-mid vowels in NFP, is specified for the low vowel in final posttonic context (see (6), (7) and (8) again). Therefore, it is only by assuming that neutralization is a mechanism of feature-change that the rules in (7) and (8) could be formalized.

\section{The NFP subsystem}

The NFP vowel subsystem must be analyzed in such a way that it is possible to account for the facts previously discussed, namely: (i) there is no existing minimal pair in the language to serve as straightforward evidence of the phonemic content of high-mid vowels /e, o/ in NFP; (ii) in certain dialects, there is a high rate of alternation between high-mid and high vowels in NFP; (iii) but for other dialects, experimental studies have shown that the rate of high vowels is, in fact, much lower than of high-mid; (iv) front high vowels in NFP tend to be blocked in certain words; (v) in northern dialects of BP, low-mid vowels may also be phonetically produced in NFP; (vi) and finally, no logical pattern has ever been found to explain the phonological motivation for the surfacing of high-mid vowels in NFP.

The configuration of three [open] features has proven to be efficient to contrast vowel height in BP. It has also been well established that [open3] is neutralized outside stressed syllables and [open2] is neutralized in word-final posttonic syllables (Wetzels 1992). Therefore, it is the sta- 
tus of [open2] in NFP that needs to be addressed: has it or has it not undergone neutralization?

Camara Jr.'s (1990) account would require the answer for this questions to be yes, but only for back vowels. However, as we have shown earlier, the possible formalization in autosegmental terms, as proposed by Wetzels (1992) is problematic (see section 2.2).

In Bisol's (2003) account, the answer would also have to be yes, i.e., [open2] has undergone neutralization, as this would explain both the lack of words that clearly contrast high-mid and high vowels, as well as the surfacing of high vowels in NFP. However, this account fails to explain the fact that front vowels are blocked from being produced as high vowels in some words (e.g., hét[e]ro, *hét [i ro 'straight'); also, if one assumes that $/ \mathrm{i}, \mathrm{u} /$ are the only underlying front and back vowels in the subsystem, it would be crucial to explain the phonological motivation for the highly frequent surfacing of [e, o] in NFP; finally, a three-vowel subsystem in NFP would not be able to account the fact that, in ND, low-mid vowels $[\varepsilon, \supset]$ also surface in NFP.

One could argue that the non-existence of minimal pairs in the language is the ultimate evidence for the non-phonemic character of /e/ and /o/ in NFP, i.e., that [open2] has undergone neutralization. This view alludes to what was proposed by Trubetzkoy (1939), to whom only distinctive properties should be considered when determining phonemic content. However, authors like Dresher (2003) have argued that that not only contrasts, but also phonological processes play a major role in defining underlying forms and the way they should be represented. My proposal here is that mid-vowel alternation in NFP is, yet, another piece of evidence against Trubetzkoy's view. Although minimal pairs are not found in the language to evidence the existence of contrast, all other aspects regarding mid-vowel alternation in NFP are better explained when assuming that both /e, o/ are, in fact, part of the subsystem.

This is similar to what has been proposed by Ribeiro (2007), who also advocates for a five vowels subsystem in NFP. However, Ribeiro defends the idea that mid-vowel alternation is a case of lexical diffusion, as her experimental study showed that only certain words and individuals were correlated to the surfacing of high vowels in NFP.

Recall that the rules proposed by Santana (2016) derive the height and place of articulation of the final posttonic vowel, in accordance to the general tendency of BP to have regressive assimilatory processes. However, both of these variables were left out of Ribeiro's analysis. When we look at the list of words listed by Ribeiro as examples of words that were always 
produced with high vowels in NFP (see (10)), we note that most of them have the necessary context to trigger the assimilation rule proposed by Santana, i.e., a high vowel in final posttonic context that shares the same place of articulation as the vowel in NFP.

(10) Words always produced with [u] in NFP (Ribeiro 2007, 155)

$\begin{array}{ll}\mathrm{id}[\mathrm{u}][\mathrm{u}] & \text { 'idol' } \\ \text { côm }[\mathrm{u}] \mathrm{d}[\mathrm{u}] & \text { 'convenient' } \\ \text { símb[u][u] } & \text { 'symbol' } \\ \text { semáf[u]r[u] } & \text { 'traffic light' } \\ \text { búss[u][[a] } & \text { 'compass' } \\ \text { síndr[u]m[i] } & \text { 'syndrome' }\end{array}$

There are two exceptions to the rule proposed by Santana on the list of words above, bússu[u]la and sindr[u]me. The first does not have a high vowel in final posttonic context. The second does not have a high vowel with the same place of articulation as the vowel in NFP. However, Bisol (1981) has observed that both /s/ and nasal consonants are correlated to the raising of mid-vowels in pretonic syllables, which might explain both of these cases.

Ribeiro's claim is not incorrect, high vowels do emerge more frequently in some words than others, but empirical analysis shows that it is not the word itself that is correlated to the way the vowel is produced, but the phonological contexts of which the vowel is part of. To assume that midvowel alternation in NFP is a case of lexical diffusion would be neglecting generalities: first, that $\mathrm{BP}$ is a language of regressive phonological processes; second, that both the raising and lowering of mid-vowels in NFP result from the same type of assimilatory rules that exist in pretonic position, yet another piece of evidence that both of the subsystem have the same configuration. Thus, a rule-based approach is much more explanatory than the diffusionist approach proposed by Ribeiro (2007) to explain mid-vowel alternation in NFP.

In autosegmental terms, if we assume that [open2] has not undergone neutralization in NFP, it is possible to, first, solve the asymmetry problem that exists in Câmara Jr.'s proposal, as the subsystem would be symmetrical, with five vowels similar to the one in pretonic context /i, e, a, o, u/ (see (5) repeated as (11) below). 
(11) Feature specification in pretonic

$\begin{array}{lccc}\text { Aperture } & \mathrm{i} / \mathrm{u} & \varepsilon / \mathrm{o}[\mathrm{e} / \mathrm{o}] & \mathrm{a} \\ \text { open1 } & - & - & + \\ \text { open2 } & - & + & + \\ \text { open3 } & - & - & +\end{array}$

Second, the general high frequency of high-mid vowels in NFP (cf. Table 1) and the fact that the surfacing of [e, o] is not predictable are strong indications that these vowels are part of the subsystem in NFP. Third, it is only by [+open2] being available that the facts observed in experimental studies can be explained through assimilatory rules (see (8) and (9)). Fourth, dialects that have a strong tendency for high vowels to be produced in NFP do not contradict the five-vowel subsystem because both assimilatory rules are variables and also because it is reasonable to assume that other phonological processes besides the assimilatory rule might also have high vowels as outcome in those dialects. ${ }^{4}$ Fifth, it becomes possible to explain why there are some words that block high vowels in NFP: the vowel is not in the underlying form and, therefore, does not surface as such, especially when taking into account that these words do not have the triggers for the assimilatory rule (neither hétero 'straight' nor tépido 'tepid', described by Câmara Jr. as words that are never pronounced with high vowels in NFP, have a high vowel that shares the same place of articulation with the mid-vowel in NFP, i.e., the context to trigger the rule proposed by Santana 2016).

Therefore, it seems reasonable to assume that the configuration that allows all these observations to be captured at the same time is the one of five vowels /a, e, i, o, u/, or, in autosegmental terms, to assume that [+open2] does not undergo neutralization in NFP.

The way this is formalized is even more straightforward than the other accounts. The neutralization rule which applies to [open3] in all pretonic vowels must also apply to all posttonic vowels, as its domain of application is the phonological word, cf. (12). Therefore, the five-vowel subsystem in NFP does not require a specific neutralization rule.

${ }^{4}$ Given that words with antepenultimate stress have a tendency for being unusual and also have a pattern of stress that it is not the default in BP, further sociolinguistic and suprasegmental studies may find some evidence for why that is so. 
(12) Unstressed vowel neutralization (Wetzels 1992)

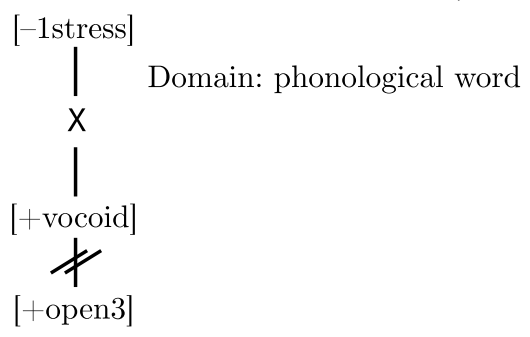

\section{Conclusion}

In this article, I addressed the issue of mid-vowels in the nonfinal posttonic subsystem of Brazilian Portuguese. The fact that it was possible to find a logical pattern and propose phonological rules for the surfacing of low-mid and high vowels in NFP, but not for high-mid vowels, alongside with other facts such as the blocking of high vowels in some words, is key evidence that high-mid vowels have a phonemic character in the subsystem.

If one only considers contrast-based evidence to define the phonemic content of mid-vowels in NFP, and not the phonological processes involved in defining vowel alternation in the position, the subsystem would be of three vowels, but a wider range of empirical data would be left unanswered. It is only by understanding mid-vowel alternation and the phonological processes it results from that it becomes evident that the underlying configuration of the NFP subsystem must be /a, e, i, o, u/.

\section{Acknowledgements}

I owe thanks to Raquel Santos, Leo Wetzels, the audience members at OCP13, two anonymous reviewers and the editors of Acta Linguistica Academica for comments on early versions of this work. All the remaining mistakes are my own.

This research was supported by Conselho Nacional de Desenvolvimento Científico e Tecnológico. Process n. 130194/2013-1. 


\section{References}

Araújo, Gabriel Antunes de. 2007. Algumas observações sobre as proparoxítonas e o sistema acentual do português [Some observations about proparoxitones and stress in Portuguese]. In G. A. d. Araújo (ed.) O acento em português: Abordagens fonológicas. São Paulo: Parábola. 37-60.

Azevedo, Milton Mariano. 2005. ortuguese: A linguistic introduction. Cambridge: Cambridge University Press.

Bisol, Leda. 1981. Harmonização vocálica, uma regra variável [Vowel harmony, a variable rule]. Doctoral dissertation. Universidade Federal do Rio de Janeiro.

Bisol, Leda. 2003. A neutralização das átonas [Unstressed vowel neutralization]. Revista Letras. Curitiba 6. 273-283.

Bisol, Leda and João Veloso. 2016. Phonological processes affecting vowels: Neutralization, harmony and nasalization. In W. L. Wetzels, S. Menuzzi and J. Costa (eds.) The handbook of Portuguese linguistics. Malden, MA \& Oxford: Wiley Blackwell. 69-87.

Cagliari, Luiz Carlos. 1997. Fonologia do português: Análise pela geometria de traços [Portuguese phonology: An analysis through feature geometry]. Manuscript.

Câmara Jr., Joaquim Matoso. 1999. Estrutura da Língua Portuguesa [The structure of Portuguese] (30th ed.). Rio de Janeiro: Vozes.

Cintra, Geraldo. 1997. Distribuição de padrões acentuais no vocábulo em português [The distribution of stress patterns in Portuguese]. Confluência 5. 82-93.

Clements, George N. and Elizabeth Hume. 1995. The internal organization of speech sounds. In J. A. Goldsmith (ed.) The handbook of phonological theory. Cambridge, MA \& Oxford: Blackwell. 245-306.

Clements, Nick. 1991. Vowel height assimilation in Bantu languages. In K. Hub-Bard (ed.) BLS 17S: Proceedings of the Special Session on African Languages Structures. Berkeley, CA: Berkeley Linguistic Society. 25-64.

Dresher, Elan. 2003. Contrast and asymmetries in inventories. In A.-M. di Sciullo (ed.) Asymmetry in grammar. Volume 2: Morphology, phonology, acquisition. Amsterdam \& Philadelphia: John Benjamins. 239-257.

Goldsmith, John A. 1990. Autosegmental and metrical phonology. Oxford \& Cambridge, MA: Blackwell.

Ribeiro, Darinka Fortunato Suckow. 2007. Alçamento das vogais postônicas não-finais no português de Belo Horizonte: Uma abordagem difusionista [The rising of non-final posttonic vowels: A diffusion approach]. MA thesis. Universidade de Federal de Minas Gerais.

Santana, Arthur Pereira. 2015. Anâlise das postônicas não-finais em São Paulo e São Luís [An analysis of non-final posttonic vowels in São Paulo and São Luís]. MA thesis. Universidade de São Paulo.

Santana, Arthur Pereira. 2016. Uma abordagem fonológica para as postônicas não-finais [A phonological approach to non-final posttonic vowels]. Domínios de Lingu@Gem 10. $494-518$. 
Trubetzkoy, Nikolai Sergejewitsch. 1939. Grundzüge der Phonologie. Göttingen: Vandenhoeck \& Ruprecht.

Vieira, Maria José. 2002. As vogais médias postônicas: Uma anâlise variacionista [Posttonic mid-vowels: A variationist analysis]. In L. Bisol and C. Brescancini (eds.) Fonologia e variação: Recortes do Português Brasileiro [Phonology and variation: Insights from Brazilian Portuguese]. Porto Alegre: EdiPucRS. 127-159.

Wetzels, W. Leo. 1992. Mid-vowel neutralization in Brazilian Portuguese. Cadernos de Estudos Lingüísticos 23. 19-55.

Wetzels, W. Leo. 2011. The representation of vowel height neutralization in Brazilian Portuguese (southern dialects). In J. Goldsmith, E. Hume and W. L. Wetzels (eds.) Tone and features: Phonetic and phonological perspectives. Berlin \& New York: De Gruyter. 331-360. 